\title{
NILAI DIDAKTIS SYAIR LAGU IER PARE PADA MASYARAKAT ETNIS SIKKA KROWE DI KABUPATEN SIKKA
}

\section{DIDACTIC VALUE OF THE IER PARE SONG BY THE SIKKA KROWE ETHNIC IN SIKKA COMMUNITY DISTRICT}

\author{
Marlin E. Lering, Gisela Nuwa, Nur Syamsiah \\ IKIP Muhammadiyah Maumere \\ Jalan Jenderal Sudirman Kelurahan Waioti, Alok Tim, Kabupaten Sikka, \\ Nusa Tenggara Timur \\ Ponsel: 085253573100; Pos-el: marlinlering85@gamil.com; \\ gustavnuwa123@gmail.com; cahayamaumere@gmail.com
}

\begin{abstract}
Abstrak
Nilai-nilai didaktif dalam syair lagu Ier pare pada masyarakat etnis Krowe merupakan suatu bentuk pengangkatan kembali nilai kearifan lokal setempat yang diyakini dapat memberikan nilai-nilai kehidupan yang tergerus oleh perubahan zaman. Tujuan penelitian ini adalah mendeskripsikan nilai-nilai didaktif dalam syair lagu Ier pare pada masyarakat etnis Sikka Krowe. Metode yang digunakan dalam penelitian ini adalah metode deskriptif dengan pendekatan kualitatif. Pengumpulan data menggunakan metode observasi dan studi kepustakaan. Analisi data dilakukan dengan langkah reduksi data, penyajian data, dan penarikan kesimpulan. Hasil penelitian terkait nilai-nilai didaktif dalam syair lagu ier pare pada masyarakat Sikka Krowe menunjukkan bahwa: Pertama, Nilai Kecerdasan atau intelektual berarti dalam menghadapi persoalan hidup hendaknya menggunakan segala akal kemampuan untuk mengatasinya. Kedua, nilai harga diri diperoleh dari proses pencarian benih yang terbaik di tempat yang jauh. Benih yang terbaik identik dengan kualitas diri seseorang. Ketiga, nilai sosial dimaknai sebagai semangat solidaritas dan memahami diri tidak dapat hidup sendirian tanpa orang lain. Keempat, nilai cita-cita hidup yang dimaknai dengan segala hal yang dikerjakan saat ini dengan tekun akan membuahkan hasil yang baik. Kelima, nilai sopan santun berarti sikap taat dan patuh terhadap hal yang disepakati bersama. Keenam, nilai kemurnian diri.
\end{abstract}

Kata-kata kunci: nilai-nilai didaktif; syair lagu; Ier Pare 


\begin{abstract}
The didactic values in the lyrics of the Ier pare song in the Krowe ethnic community are a form of reenacting the values of local wisdom which are believed to be able to provide the values of life that have been eroded by the times. The purpose of this study is to describe the active values in the song lyrics of Ier pare in the Sikka Krowe ethnic community. The method used in this research is descriptive method with qualitative approach. Data collected are using observation and literature study. Data analysis is carried out using data reduction, data presentation, and conclusion drawing. The results of research related to the didactic values in the poetry of the song Ier Pare in the Sikka Krowe community show that: First, the value of intelligence or intellectual means in dealing with life problems requires all reasonable abilities to overcome those problems. Second, the value of self-esteem which is obtained from the process of searching for the best seeds in distant places. The best seeds are synonymous with the qualities of a person. Third, social values are interpreted as a spirit of solidarity and understanding that we cannot live alone without other people. Fourth, the idea of life, meant with all the things that are done at this time diligently that will produce good results. Fifth, the value of courtesy that means being obedient and obedient to what is mutually agreed upon. Sixth, the value of self-purity.
\end{abstract}

Keywords: directive values; song lyrics; Ier Pare

\section{Pendahuluan}

Negara Indonesia pada dasarnya kaya akan adat dan budaya. Kekayaan adat dan budaya ini menjadikan Indonesia sebagai salah satu negara yang memiliki keanekaragaman suku, ras, agama yang dapat menarik wisatawan baik domestik maupun mancanaegara. Adat dan budaya ini dikenal dengan isitilah kearifan lokal. Kearifan lokal merupakan bagian dari budaya suatu masyarakat yang tidak dapat dipisahkan dari bahasa masyarakat lokal itu sendiri (Ahmad Baedowi, 2015: 55). Kearifan lokal itu terdapat pada cerita rakyat, lagu, peribahasa, dan permainan rakyat (Titien Agustina, 2019: 120).

Kearifan lokal juga dimiliki oleh masyarakat Sikka Krowe yang merupakan salah satu etnis di wilayah Kabupaten Sikka, Nusa Tenggara Timur, dan masih terus dipertahankan hingga saat ini. Etnis ini dianggap sebagai salah satu dari etnis Mukang. Etnis Mukang dibagi menjadi empat suku, yaitu Sikka, suku Krowe, suku Mukang dan suku Muhang (Gisela Nuwa, 2020: 6). Setiap etnis memiliki kearifan lokal berupa lagu berdasarkan budaya setempat. Etnis Sikka Krowe memiliki banyak lagu daerah sebagai warisan budaya yang kaya akan makna dan nilai-nilai yang dipetik. Jenis lagu-lagu ini biasanya dinyanyikan pada saat pelaksanaan upacara adat. Lantunan lagu ini tidak terlepas dengan peralatan musik kampung yang digunakan sebagai bentuk satu kesatuan atau harmonisasi dari masyarakat yang 
terdapat di dalamnya (Gisela Nuwa, 2020: $5)$.

Salah satu syair lagu yang dimaksud adalah Ier Pare. Ier Pare merupakan syair lagu yang dinyanyikan oleh masyarakat pada saat mengetam padi. Lagu ini dinyanyikan secara bersama-sama atau berkelompok di kebun yang dipimpin oleh seseorang tua adat yang disebut Sora dan sebagai peringatan terhadap pengorbanan dari Rebo putri yang dikorbankan oleh Ayahnya menjadi padi (cerita rakyat masyarakat setempat). Selain itu, juga sebagai bentuk ucapan syukur dari masyarakat setempat kepada Tuhan sang pencipta yang telah memberikan kelimpahan makanan. Jika dilihat dari asal katanya, Ier merupakan proses penanaman sementara pare artinya padi. Jadi Ier Pare merupakan proses penanaman padi.

Berdasarkan perspektif nilai, kearifan lokal merupakan inti kebudayaan itu sendiri. Sistem nilai memiliki kekuatan untuk mengatur, mengendalikan, memberikan, arah para perilaku atau perbuatan dari individu (H. Iin Wariin Basyari, 2014). Sementara didaktif berarti proses pengubahan sikap dan tata laku seseorang atau kelompok orang dalam usaha mendewasakan manusia melalui upaya pengajaran dan pelatihan
(Depdiknas, 2007). Nilai didaktif erat hubungannya dengan tujuan akhir dari pendidikan yang tertuang dalam UUD RI Nomor 20 tahun 2003 tentang sistem Pendidikan Nasional. Disebutkan bahwa pendidikan merupakan usaha sadar dan terencana untuk mewujudkan suasana belajar dan proses pembelajaran agar peserta didik secara aktif mengembangkan potensi dirinya untuk memiliki kekuatan spiritual keagamaan, pengendalian diri, kecerdasan, akhlak mulia serta ketrampilan yang diperlukan dirinya, masyarakat bangsa dan Negara (Mulyasa, 2008: 50). Ini berarti bahwa pendidikan mencakup proses pengubahan sikap dan tingkah laku manusia, mengembangkan potensi diri yang dimiliki, serta kedewasaan secara intelektual. Jalan yang ditempuh dapat melalui menggali potensi-potensi yang terdapat pada kearifan lokal setiap daerah. Jenis-jenis nilai didaktis mencakup, (1) intelektual/kecerdasan, (2) keterampilan, (3) harga diri, (4) sosial/hubungan kemasyarakatan, (5) moral, (6) keindahan, (7) keagamaan, (8) penguasaan diri/kestabilan emosi, (9) tingkah laku/adat sopan santun. (10) cita-cita (Ria Kasanova, 2019:17).

Ummu F. Ria Lestari (2012: 248) menjelaskan hasil penelitiannya tentang 
unsur didaktis dalam syair lagu rakyat Papua, yaitu a) unsur intelektual, dalam hal ini adalah sikap tekun atau bersungguh-sungguh dalam menuntut ilmu dan sikap gotong royong (kerja sama); b) unsur etika dan agama, dalam hal ini adalah sikap menghormati orang tua dan sikap bersahabat; dan c) unsur filosofis, dalam hal ini adalah sikap cinta kepada kampung (tanah air).

Berhadapan dengan kenyataan ini peneliti berusaha menggali nilai-nilai didaktis pada syair lagu ler pare yang selama ini belum pernah digali atau diteliti. Syair lagu ini pada dasarnya memiliki makna yang sangat mendalam bagi masyarakat Sikka Krowe. Hal ini terutama bagi generasi sekrang ini yang cenderung dipengaruhi oleh kemajuan ilmu pengetahuan dan teknologi. Isi syair lagu ini mengajak orang untuk selalu hidup konsisten pada prinsip hidup yang sudah dijalankan sebagaimana yang terdapat dalam nilai didaktis. Selain itu, syair lagu ini merupakan bagian dari khasana budaya bangsa yang perlu diangkat sehingga masyarakat Sikka secara khusus dan secara nasional mengenalnya. Hal yang paling penting adalah sumbangsihnya dalam pendidikan karakter bangsa saat ini yang sedang mengalami perubahan.
Keseluruhan data dalam penelitian ini diambil dari data primer dan sekunder. Sumber data primer diperoleh dari kepala adat yang diyakini masih memiliki pengetahuan tentang syair lagu ier pare. Selain itu, data diperoleh dari tokoh masyarakat Sikka Krowe dalam menggali nilai-nilai dari syair ier pare. Sumber data primer diperoleh dari literatur kuno hasil tulisan masyarakat atau tokoh adat terkait syair lagu ier pare dan referensi lain berupa buku teks dan jurnal. Atas dasar inilah peneliti meyakini dapat mengungkapkan niai-nilai didaktis syair lagu ier pare pada masyarakat Sikka Krowe.

\section{Landasan Teori \\ 2.1 Nilai Didaktis}

Menurut Muchson dan Samsuri (2015:21), kata nilai berasal dari kata valere dalam bahasa Latin atau valoir dalam Prancis Kuno, yang biasa diartikan sebagai 'harga' atau 'taksiran'. Secara harfiah nilai merupakan harga yang ditimbulkan dari penilain terhadap sesuatu. Nilai itulah yang akan menentukan kualitas dari hal atau sesuatu yang menjadi objek penilaian sekaligus memberikan kesimpulan akhir bagi individu terhadap individu yang lain. Dalam lagu ier pare, nilai itu selalu dihubungkan dengan prinsip hidup yang diwariskan oleh budaya. 
Pada tataran tertentu, nilai dapat diklasifikasikan berdasarkan sifat-sifat nilai pada tataran hierarki atau gradasi yang di ataranya; nilai terminal dan nilai instrumental, nilai intrinsik dan nilai ekstrinsik, nilai personal dan nilai sosial, serta nilai subjektif dan nilai objektif. Dalam bidang kehidupan, katagori nilai adalah; (a) nilai teoritis, (b) nilai ekonomis (c) nilai estetis (d) nilai sosial (e) nilai politik (f) nilai agama. Dalam lagu ier pare, nilai yang paling dalam yaitu estetis, sosial, dan agama.

Menurut Kamus Besar Bahasa Indonesia (KBBI), didaktis adalah sesuatu yang bersifat mendidik. Ngalim Purwanto (dalam Siswanto, et al, 2006:7) membagi pendidikan menjadi dua segi, yaitu pendidikan jasmani dan pendidikan rohani. Dalam konteks syair lagu ier pare pendidikan yang perlu diangkat yaitu kerohanian yang dapat mengubah karakter masyarakat setempat. Tentu hal ini harus berorientasi pada nilai positif dan dapat menimbulkan kecakapan baru pada diri orang lain. Kecakapan baru itu bukan berupa suatu keterampilan, tetapi berupa suatu tindakan yang baik yang mencerminkan isi atau konten dari syair lagu tersebut. Maka hubungannya dengan penelitian ini, pada dasarnya mengupas tentang pendidikan yang tidak tertulis berlangsung pada masyarakat adat. Dengan kata lain, melalui syair adat seseorang dapat memperoleh pendidikan yang bermacam-macam tergantung pada nilai apa yang terkandung di dalamnya.

Berdasarkan cakupan pendidikan yang diuraikan di atas dapat disimpulkan bahwa unsur-unsur didaktis yang dianalisis meliputi moral, filosofi, agama, dan intelektual. Etika moral mencoba menganalisis konten pendidikan dari perspektif nilai-nilai luhur demi mewujudkan keluhuran budi masyarakat penganutnya. Nilai-nilai luhur tersebut merupakan pembeda yang lahir dari adat istiadat berupa syair adat. Alwi, et al. (2002:309) mendefenisikan etika sebagai ilmu tentang apa yang baik dan apa yang buruk dan tentang hak dan moral (akhlak). Dengan demikian, nilai etika dalam perspektif budaya terletak pada pesan apa yang terdapat dalam literatur budaya, entah berupa syair lagu maupun ungkapanungkapan lainnya. Pada umumnya, berbicara tentang nilai yang baik dan buruk serta hak dan moral (akhlak).

Menurut Syahrul Kirom (2012: 10), filsafat berarti suatu teori atau analisis logis tentang suatu peristiwa yang mendasari pemikiran, pengetahuan, dan alam semesta. Syair adat masyarakat Sikka Krowe mengandung makna filosofis tentang nilai 
yang belum terungkap namun memiliki kebenaran universal. Alwi, et al (2002: 317) menguraikan filosofis itu sebagai bentuk pengejawantahan dari kata falsafah hidup masyarakat setempat. Dalam syair lagu ier pare, nilai filsafat yang dimaksudkan adalah proses berpikir tentang suatu hal yang mengarah pada akal budi atau pengalaman yang diambil hikmahnya yang kemudian dijadikan prinsip hidup.

\subsection{Lagu Rakyat}

Aminoh Jehwae (2012: 20) memaparkan konsep lagu rakyat sebagai salah satu bentuk karya sastra yang terus berkembang dan bergerak dinamis. Lagu rakyat adalah ekspresi pribadi manusia, baik berupa pengalaman, pikiran, perasaan, ide, semangat, maupun keyakinan dalam suatu bentuk karya dan hasrat yang membangkitkan pesona. Lagu rakyat adalah ragam suara yang berirama (dalam bercakap, bernyanyi, membaca, dan sebagainya). Lagu rakyat terdiri atas susunan kata-kata pilihan yang mudah dipahami, disukai, dan dikenali oleh banyak orang, (Yosaphat Yogi Tegar Nugroho, 2021: 15).

Lagu rakyat ier pare adalah lagu (nyanyian) yang sudah merakyat, (dimiliki, hidup, dan berkembang secara merakyat). Lagu tersebut sangat sederhana, mudah dicerna dan diangkat dari budaya leluhur serta spesifikasinya khas dari sesuatu daerah Sikka Krowe. Perkembangannya melalui dari mulut ke mulut, turun-temurun dari generasi ke generasi. Syair lagu ier pare diwariskan secara turun temurun. Lagu rakyat tersusun atas lirik dan bait. Setiap bait, bahkan setiap liriknya mengandung makna. Lagu rakyat ini juga memiliki kandungan makna seperti halnya lagu pada umumnya. Sebagai hasil budaya, lagu rakyat mengandung makna dan nilai-nilai budaya rakyat (Subardi, 2008: 15).

Yosaphat Yogi Tegar Nugroho, (2021) menjelaskan syair dan lirik lagu merupakan dua hal yang tidak dipisahkan. Lirik lagu (populer maupun daerah) termasuk karya seni yang tidak hanya dilihat sebagai nyanyian tetapi juga bagian dari karya sastra yang memiliki nilai edukatif bagi pengikutnya. Keseluruhan cerita dalam lirik lagu mengungkapkan peristiwa yang dapat diamati oleh pancaindera dan memiliki korelasi dengan kehidupan manusia. Selain itu juga mengungkapkan peristiwa yang terjadi di dalam batin, pikiran, dan anganangan pengarang. Dengan demikian, syair lagu ier pare merupakan bagian dari karya sastra Sikka Krowe yang kaya akan nilai edukasi bagi masyarakatnya. 


\section{Metode Penelitian}

Metode yang digunakan dalam penelitian ini adalah kualitatif deskriptif. Metode ini dimaksudkan agar penelitian ini menjadi lebih terarah. Metode deskripsi merupakan suatu metode dalam meneliti status sekelompok manusia, suatu objek, suatu set kondisi, suatu sistem pemikiran ataupun suatu kelas peristiwa pada masa sekarang, (Subandi, 2011: 10). Pengambilan data dilakukan dalam keadaan yang sewajarnya dan dikenal dengan sebutan "pengambilan data secara alamiah atau natural". Sumber data diperoleh dari data primer yaitu data yang langsung dari subjek dan sumber data sekunder yaitu data yang berasal dari buku/teks/literatur lain yang mendukung penelitian ini. Pengumpulan data menggunakan metode observasi dan wawancara dengan tua adat dan literaturliteratur lain yang memiliki hubungan dengan syait lagu ier pare. Analisis data dilakukan dengan langkah reduksi data, penyajian data, dan penarikan kesimpulan.

\section{Pembahasan}

Lagu rakyat adalah nyanyian yang sudah merakyat, hidup, dan berkembang secara merakyat. Lagu rakyat juga merupakan bagian yang tidak dipisahkan dengan syair adat. Syair adat ini memiliki sifat sederhana, mudah dicerna dan diangkat dari budaya leluhur. Ciri dan spesifikasinya khas dari sesuatu daerah. perkembangannya melalui dari mulut ke mulut, turun-temurun dari generasi ke generasi. Interpretasi makna terdapat beraneka ragam, tergantung dari sudut pandang dan cara memaknai lagu tersebut.

Lagu rakyat adalah salah satu bagian dari budaya rakyat. Sebagai hasil budaya, lagu rakyat mengandung makna dan nilai-nilai budaya rakyat. (Menurut Subardi, 2008: 6). Pada syair lagu ier pare etnis Sikka Krowe juga merupakan sebuah lagu rakyat yang sangat dekat dengan masyarakat Sikka Krowe yang memiliki makna yang sangat mendalam. Berikut merupakan syair lagi Ier pare pada masyarakat Etnis Krowe;

1) Oe le le... (uma morun mate tota tana wawa dota)

Eio...o..o (uma morun mate tota tana wawa dota)

2) Ele le le le le le le E (neang wawa dota pare menik teli pitu) Eio...o..o (neang wawa dota pare menik teli pitu)

3) Ele le le le le le le E (neang pare ropo ata mekot to'i le'u) Eio...o..o (neang pare ropo ata mekot to'i le'u)

4) Ele le le le le le le E (nona pare ropo hi'a hida waten halang) 
Eio...o..o (nona pare ropo hi'a hida waten halang)

5) Ele le le le le le le E (nona pare tia beta beli nora naran)

Eio...o..o (nona pare tia beta beli nora naran)

6) Ele le le le le le le E (rebo nora odang, odang toda wawa dang)

Eio...o..o (rebo nora odang, odang toda wawa dang)

Secara etimologis, nilai merupakan pandanan kata value (bahasa Inggris), (Mustari Mustafa, 2011: 15). Dalam kehidupan sehari-hari, nilai merupakan sesuatu yang berharga, bermutu, menunjukkan kualitas, dan berguna bagi manusia. Adapun didaktis menurut KBBI merupakan pendidikan. Nilai dan pendidikan merupakan sesuatu yang bermakna dan sangat dekat dengan kehidupan manusia itu sendiri. Kedekatan manusia dengan nilai dan pendidikan terletak pada pengalaman hidup yang lahir dari budaya setempat. Pada etnis Sikka Krowe terdapat nilai didaktis yang sering dijalankan dan bahkan sebagai sumber pendidikan bagi para penerusnya. Salah satu nilai didaktis dalam etnis Sikka Krowe dapat dilihat dalam syair Ier Pare. Nilai didaktis dalam syair lagu Ier Pare pada masyarakat etnis Sikka Krowe sebagai berikut:

\section{a. Nilai Kecerdasan/Intelektual}

Nilai kecerdasan dalam syair lagu ier pare terdapat pada lirik berikut:
Oe le le... (uma morun mate tota tana wawa dota)

Eio...o..o (uma morun mate tota tana wawa dota)

Nilai didaktis di dalam syair lagu Ier Pare mengandung ajaran yang mendidik dan menuntun manusia agar memiliki kecerdasan. Hal ini ditemukan pada syair pertama yang diulang hingga dua kali. Uma morun mate yang berarti kebun yang tidak menghasilkan makanan dan tota tana wawa dota yang bermakna mencari makanan hingga ke Dota (salah satu daerah di wilayah di Kab, Ende). Hal ini menyiratkan bahwa manusia harus menggunakan segala akal dan budi untuk bertindak ketika dihadapkan dengan persoalan hidup. Lahan perkebunan yang tidak lagi membawakan hasil mesti diupayakan sekuat tenaga dengan menggunakan segala akal dan budi agar dapat memperoleh hasil yang bagus. Persoalan yang masyarakat Sikka Krowe pada saat itu adalah kekurangan makanan. Hal ini merupakan tahapan rasionalitas manusia (animal rasional) yang selalu mencari solusi pada saat berhadapan dengan persoalan hidup. Berkaitan dengan hal ini, Putri Ambarwati menjelaskan nilai syair lagu Madura dalam hubungannya dengan 
kecerdasan intelektual masyarakat Madura pada karakternya untuk selalu hidup bertanggung jawab terhadap persoalan hidupnya, (Putri Ambarwati, 2019: 60). Manusia memiliki akal yang dibentuk dalam tradisi untuk bertindak menunjukkan nilai kecerdasan dalam menjalankan hidupnya. Dengan kata lain, kecakapan merupakan suatu proses untuk menyaring dan memecahkan persoalan yang datang, (Ali 1992: 107).

\section{b. Nilai Harga Diri}

Sutriadi (2019: 37) dalam penelitiannya tentang representasi nilainilai moral dalam syair lagu daerah Madura mengupas tentang harga diri sesorang tak tergantikan oleh apapun. Identitas seseorang terletak pada kasana budaya dan agama yang melekat dalam diri orang yang bersangkutan. Nilai Harga diri merupakan nilai yang diagungkan. Dewasa ini, harga diri kerap menjadi alasan mendasar orang untuk bertikai.

Berkaitan dengan hal itu, syair kedua lagu ier pare mengungkapkan harga diri itu identik dengan benih yang baik dan diperjuangkan eksistensinya dengan berbagai cara seperti berikut;

Ele le le le le le le E (neang wawa dota pare menik teli pitu)
Eio...o..o (neang wawa dota pare menik teli pitu)

Syair tersebut bermakna, bibit yang telah ditemukan di Dota (daerah yang terdapat di Kabupaten Ende), adalah bibit terbaik. Ini berarti benih yang baik menunjukan jati diri seseorang melalui usaha dan kerja keras dalam memperolehnya. Syair di atas telah mengajarkan kepada masyarakat tentang pentingnya menjaga harga diri seperti benih yang baik yang selalu dicari dan dihargai oleh orang lain. Individu terbaik adalah yang mampu menjaga harga diri, sama seperti benih yang unggul dalam bidang pertanian.

\section{c. Nilai Sosial}

Nilai sosial juga ditemukan dalam syair lagu Ier pare pada bait pertama dan kedua. Nilai sosial yang dimaksudkan di sini termanifestasi dalam aktivitas pencarian bibit secara bersama-sama hingga ke Kabupaten Ende, salah satu kabupaten yang terdapat di pulau Flores dengan jarak yang cukup jauh dari kabupaten Sikka. Letaknya di bagian utara kabupaten Sikka. Selain itu juga terdapat perbedaan kultur dan karakter masyarakatnya. Perbedaan kultur, geografis, budaya, bahasa serta adat 
istiadat sebenarnya bukan menjadi persoalan dalam menjalin hubungan masyarakat antara kedua daerah ini. Pola relasi yang ditunjukkan selalu mengedepankan sikap harmonis dan mengedepankan rasa kepercayaan. Tanda perjanjian sosial yang dipakai oleh kedua kabupaten ini adalah benih padi dan jagung. Benih ini identik dengan tanda kolektivitas sosial yang mempersatukan masyarakat Sikka dengan Masyarakat Ende. Hal ini patut menjadi ajaran yang baik bagi masyarakat saat ini bahwa manusia harus memiliki hubungan yang baik dengan sesama karena manusia tidak dapat hidup sendirian.

Wina (2018: 51) dalam ulasannya tentang nilai sosial membedakan dua hal yaitu pertama, tolong menolong terhadap sesama sebagai animal socius dan kedua, memaafkan semua kesalahan terhadap sesama manusia. Kedua kriteria ini menunjukkan kualitas diri manusia sebagai makhluk individu sekaligus makhluk sosial.

\section{d. Nilai Cita-Cita}

Menurut Effendi (1998: 55), adat merupakan nilai-nilai budaya, normanorma hukum, pandangan hidup dan cita-cita, pengetahuan dan keyakinan. Nilai cita- cita merupakan nilai yang menunjukkan kemampuan mencapai tujuan dengan kemauan yang keras. Dalam perspektif syair lagu Ier pare, terdapat korelasi yang jelas antara hal yang diupayakan oleh masyarakat Sikka Krowe dalam memperoleh bibit yang baik dengan kerinduan akan memperoleh hasil yang banyak. Syairnya secara jelas terdapat pada bait ke- 4 sebagai berikut:

Ele le le le le le le E (neang pare ropo ata mekot to'i le'u)

Eio...o..o (neang pare ropo ata mekot to'i le'u)

Syair di atas memiliki makna bahwa bibit yang unggul itu harus segera ditanam sebelum musim tanam berlalu. Dengan menepati tuntutan ini, masyarakat setempat meyakini hasil panen yang akan diperoleh pasti melimpah. Harapan akan hasil panen yang banyak dapat dikategorikan sebagai cita-cita yang mesti diraih dan tujuan akhir dari usaha mereka. Selain itu, melalui syair ini diajarkan bahwa sebuah pekerjaan harus memiliki tujuan akhir yang ditunjukkan dengan hasil panen yang melimpah. Nilai cita-cita ini juga sejalan dengan yang disampaikan oleh Haris Wua (2015: 6) dalam tuturan kabhanti manari pada masyarakat Muna. Kabhanti manari mengajak masyarakat untuk hidup dalam prinsip 
dan tujuan sebagaimana yang terdapat dalam makna tuturnya.

Bait kelima syair lagu ini mengupas tentang tujuan dari sebuah proses pekerjaan. Tujuan itu harus tercapai oleh setiap orang yang berani untuk memulai sebuah pekerjaan tertentu. Syairnya sebagai berikut:

Ele le le le le le le E (nona pare tia beta beli nora naran)

Eio...o..o (nona pare tia beta beli nora naran)

$$
\text { Penggalan syair tersebut }
$$
bermakna bahwa saat menanam padi harus memiliki tujuan atau cita-cita yang jelas, bukan asal menanam, bukan hanya mencoba-coba, melainkan harus memiliki perencanaan yang matang. Dengan memegang prinsip demikian, pada akhirnya akan mendapkan hasil yang maksimal.

\section{e. Nilai Sopan Santun}

Putri Ambarwati (2019: 58) menjelaskan nilai sopan santun dalam syair lagu "Resere Penang", "Caca Aghuna”, "Bing Ana'”, “Tandhu' Majheng", dan "Pajjhar Lagghu", berisi tentang nasihat agar masyarakat berperilaku baik dan berbicara sopan santun terhadap sesama. Dalam syair lagu ier pare juga terdapat makna sopan santun terhadap sesama seperti terdapat dalam yair berikut ini:

Ele le le le le le le E (nona pare ropo hi'a hida waten halang)

Eio...o..o (nona pare ropo hi'a hida waten halang)

Syair lagu di atas bermakna dalam menanam padi haruslah dengan cekatan dan tidak boleh terburu-buru. Cekatan yang dimaksudkan pada tataran ini berhubungan dengan sikap tidak boleh saling mengharap atau bergantung dalam menyelesaikan pekerjaan. Sikap taat dan patuh terhadap perintah orang tua menjadi mutlak dimiliki oleh seseorang. Sikap taat dan patuh kepada orang tua merupakan bagian dari sikap penuh syukur atas apa yang dikerjakan. pernyataan ini identik dengan pribadi yang sopan santun sebagai nilai dasar dari kehidupan manusia. Individu yang tahu bersyukur merupakan pribadi yang paham akan nilai sopan santun dan bertingkah laku. Nilai sopan santun tidak hanya melalui tutur kata semata melainkan harus diwujudnyatakan dalam tindakan riil dan diterapkan dalam kehidupan bermasyarakat. Orang yang beradab berarti memahami nilai sopan santun. 


\section{f. Nilai Kemurnian Diri}

Sadik (2011: 15) menjelaskan kemurnian diri bagi orang Madura merupakan arghââna atau ajina aba' yang merupakan bagian dari kearifan lokal dan sama dengan pembinaan budi pekerti. Budi pekerti merupakan cerminan perilaku manusia yang senantiasa menjaga diri dari pengaruh buruk. Perilaku manusia ini sangat diperlukan dalam memajukan diri, dan memajukan masyarakat dan bangsa terutama dari serangan atau gempuran perubahan. Dalam syair lagu ier pare terdapat nilai harga diri sebagai cerminan dari masyarakat Sikka Krowe dengan simbol rebo dan odang. Hal ini terdapat dalam syair bait terakhir sebagai berikut:

Ele le le le le le le E (rebo nora odang, odang toda wawa dang) Eio...o..o (rebo nora odang, odang toda wawa dang)

Bait terakhir syair di atas bermakna bahwa rebo dan Odang yang merupakan dua jenis padi tersebut telah selesai diketam dan disimpan dengan baik di dalam lumbung padi agar terhindar dari serangan hama. Nilai yang dipetik adalah masyarakat mesti menjaga diri dengan sebaik mungkin agar terhindar dari hal-hal yang tidak baik. Harga diri seseorang terletak pada prinsip hidup yang dihidupi sesuai dengan norma yang berlaku di tengah masyarakat. Menjaga diri tetap suci merupakan bagian dari citra Allah agar tetap berharga di mata sesama.

\section{Penutup}

Kearifan lokal merupakan kekayaan bangsa yang harus tetap dijaga demi menjaga nilai-nilai yang akan bermanfaat bagi masyarakat. Syair lagu ier Pare dari etnis Sikka Krowe Kabupaten Sikka, NTT merupakan salah satu kearifan lokal menjadi salah satu kekayaan daerah juga bangsa serta memberikan nilai yang tersirat. Nilainilai ini adalah nilai cita cita, nilai harga diri, nilai sosial, nilai sopan santun dan nilai kecerdasan. Semua nilai yang telah disebutkan tersebut diharapkan memiliki kebermanfaatan bagi masyarakat etnis Sikka Krowe dan masyarakat secara umum sebagai warisan bangsa. 


\section{Daftar Pustaka}

Agustina, Titien. 2018. "Membangun Manajemen Kearifan Lokal (Studi pada Kearifan Lokal Orang Banjar)". Jurnal Riset Inspirasi Manajemen dan Kewirausahaan. Vol. 2, No. 2: hal. 120-129.

Ali, M. Natsir. 1984. Dasar-dasar Ilmu Mendidik. Jakarta: Mutiara

Alwi, Hasan, et al. 2002. Kamus Besar Bahasa Indonesia edisi ke-3. Jakarta: Balai Pustaka. Departemen Pendidikan Nasional.

Ambarwati, Putri. 2019. "Nilai SosialMasyarakat Madura Dalam Kumpulan Syair Lagu Daerah Madura". Satwika, Vol. 3, No. 1. Hal. 54-64.

Baedowi, Ahmad. 2015. Calak Edu 4: Esai-esai Pendidikan 2012-2014. Pustaka Alvabet. Diakses tanggal 2 April 2020.

Basyari, H. Iin Wariin. 2014. NILAINILAI KEARIFAN LOKAL (LOCAL WISDOM) TRADISI MEMITU PADA MASYARAKAT CIREBON (Studi Masyarakat Desa Setupatok Kecamatan Mundu), Jurnal Edunomic, Vol. 2, No. 1, Hal. 4756.
Darmawati, Besse. 2008. Nilai Religius dalam Lagu-lagu Bugis. Makassar: Balai Bahasa Ujung Pandang.

Depdiknas. 2007. Kamus Besar Bahasa Indonesia. Jakarta: Balai Pustaka.

Effendi, dkk. 1998. Perubahan Nilai Upacara Tradisional pada Masyarakat Pendukungnya (Upacara Adat Perkawinan Suku Bangsa Lembak di Kotamadya Bengkulu). Bengkulu: Departemen Pendidikan dan Kebudayaan RI.

Jehwae, Aminoh. 2012. Membina Kedamaian Di Wilayah Sempadan Selatan Thailand Melalui Lagu Rakyat Melayu Patani, Jurnal Penelitian Pendidikan, Vol. 11, No. 2, Hal. 1-12.

Kasanova, Ria. 2019. Nilai-Nilai Didaktis dalam Novel "Matahari Di Atas Gilli" Karya Lintang Sugianto, Jurnal Pendidikan Bahasa dan Sastra Indonesia, Vol. 6, No. 2. Hal. 47-58.

Kirom, Syahrul. 2011. Filsafat Ilmu dan Arah Pengembangan Pancasila: Relevansinya Dalam Mengatasi Persoalan Kebangsaan, Jurnal Filsafat Vol. 21, No. 2, hal. 99-17.

Lestari, Ummu Fatimah Ria. 2012. Unsur Didaktis Dalam Syair Lagu Rakyat Papua, ATAVISME, Vol. 15, No. 2, Edisi Desember 2012: hal. 247-259.

Muchson, Abdurrohman Samsuri. 2015. Dasar-Dasar Pendidikan Moral Basis Pengembangan Pendidikan 
Karakter, Yogyakarta: Ombak Press.

Mulyasa. 2008. Filsafat Pendidikan Meneropong Undang-undang Nomor 20 Tahun 2003 tentang Sistem Penddikan Nasional. Jakarta: Remaja Rosda Karya.

Mustari, Mustafa. 2011. Konstruksi Filsafat Nilai: antara Normatifitas danRealitas, Cet. I. Makassar: Alauddin Pers.

Nugroho, Yosaphat Yogi Tegar. 2021, Karakteristik Lagu Rakyat dan Pentingnya Pengarsipan Kesenian Lokal Indonesia, Jurnal Sains, Teknologi, Masyarakat dan Jejaringan, Vol. 3, No. 2, Hal. 146155.

Nuwa, Gisela. 2020. Lokal Geniu Po'o. Maumere: IKIP Muhammadiyah Maumere.

Nuwa, Gisela. 2020. Nilai-Nilai Kearifan Lokal Gong Waning Pada Masyarakat Etnis Sikka Krowe Sebagai Sumber Pendidikan Karakter, Jurnal EduTeach: Jurnal Edukasi dan Teknologi Pembelajaran, Vol. 1, No. 2, Hal. 48-53

Sadik, A. Sulaiman. 2011. Madura oh Maduraku. Pamekasan: Sinar Pustaka Jaya.

Siswanto, Sukardi Gau, Awalistiyani Irma K. 2006. Unsur Didaktis dalam Cerita Rakyat Nabire dan Enarotali. Jayapura: Balai Bahasa Jayapura.

Subardi. 2008. "Mengenal Musik Rakyat Papua dengan Lagu Rakyat dan Alat Musik Tradisionalnya.”
Makalah Lokakarya Pelatihan Musik Rakyat Daerah Papua Tahun 2008. Jayapura.

Subardi. 2011. Deskriptif Kualitatif Sebagai Suatu Metode Dalam Penelitian Pertunjukan, Jurnal Harmonia, Vol. 11, No. 2, Hal. 173-179.

Sutriadi. 2019. "Representasi Nilai-Nilai Moral Dalam Syair Lagu Daerah Madura". Nosi, Vol. 7, No. 1. Hal. 30-39.

Wawengkang, Nontje Deisye. 2007. "Nilai-Nilai Didaktis dalam Lirik Lagu Daerah Minahasa", dalam Jurnal Kawanua Terbitan Pertama Tahun 2007, hlm. 138-155. Manado: Balai Bahasa Provinsi Sulawesi Utara.

Win. 2018. "Nilai Moral dan Sosial Dalam Album Paradox Karya Isyana Saraswati". Diksatrasia, Vol. 2, No.1. hal. 46-54.

Wua, Haris. 2015. Bentuk dan Makna Turturan Kabhanti Manari Pada Masyarakat Muna, Jurnal Humanika No. 15, Vol. 3, hal. 120. 